\title{
Infrared reflectance spectroscopy as an analytical technique for the study of residues on stone tools: potential and challenges
}

\author{
${ }^{* 1}$ Linda C. Prinsloo, ${ }^{2}$ Lyn Wadley and ${ }^{3}$ Marlize Lombard \\ ${ }^{1}$ Physics department, University of Pretoria, Private Bag X20, Hatfield 0028, South Africa. linda.prinsloo@up.ac.za \\ ${ }^{2}$ Institute for Human Evolution and the School of Geography, Archaeology and Environmental Studies, University of the \\ Witwatersrand, Private bag 3, WITS 2050. Lyn.Wadley@wits.ac.za \\ ${ }^{3}$ Department of Anthropology and Development Studies, University of Johannesburg, PO Box 524, Auckland Park Campus, \\ Johannesburg 2006, South Africa.mlombard@uj.ac.za
}

FTIR (Fourier transform infrared) spectroscopy is a non-destructive analytical method that has been used successfully to analyse both inorganic and organic archaeological material. Using a microscope attachment has the additional benefit of analysing very small spots (diameter $100 \mu \mathrm{m}$ ) directly on an artefact without sample preparation or destruction. It is therefore a suitable method to study residues on prehistoric stone tools. However, using a microscope without an ATR (attenuated total reflection) microscope objective, results in a combination of reflection and transmission/absorbance FTIR spectra, which is not always as easy to interpret as directly measured transmission/absorbance spectra. In order to improve the interpretation of spectra recorded on archaeological samples, the method was tested with replicated Middle Stone Age stone points used during hunting and butchery experiments on parts of a blue wildebeest (Connochaetes taurinus) published in 2004 (Lombard et al., 2004). In this case, the residues on the tools were known and postdepositional contamination was eliminated. Additional samples of the organic materials, and the minerals from which the tools were made were also available. Therefore, we could assess the viability of FTIR reflectance spectra for distinguishing between bone, fat and protein residues.

Keywords: FTIR reflectance spectroscopy, stone tools, animal residues 


\section{Introduction:}

Detecting, identifying and interpreting micro-residues on Middle Stone Age or Middle Palaeolithic stone tools is never an easy or straight-forward exercise. Nondestructive micro-residue analysis on archaeological stone tools is mostly done using high-power, reflected light microscopes (e.g., Hardy and Moncel, 2011; Langejans, 2012, Lombard, 2011). Blind test results attest to the general reliability of the identification of micro-residue types left on stone tools as a result of their use and/or hafting using reflected light microscopy (Hardy and Garufy, 1998; Lombard and Wadley, 2007; Monnier et al., 2012, Wadley, et al., 2004). To increase the dependability of interpretations, concomitant support for the identification of such residues should be sought. For example, the repetitive clustering of attendant residues, such as the combination of fat, blood, bone, and animal tissue on a tool portion provides a far more secure interpretation of an animal residue type than any single residue (Wadley and Lombard, 2007). This approach is particularly relevant to archaeological contexts where some residues may be partially degraded and where the potential of ancient, post-depositional or post-excavation contaminants is high (Langejans, 2011).

In some cases the removal and destruction of ancient residues on stone tools for specific morphological or biochemical analysis are warranted. Yet, it is our contention that - depending on the quality and certainty of results, age of the material, sample size and research question - non-destructive analyses remain one of the most responsible, contextual and informative approaches. Destructive processes are often focused on extracting only certain residue types, for example starch grains (e.g., Li et al., 2013), or animal proteins (e.g., Högberg et al., 2009), paying little attention to other residues, and destroying or disturbing their in situ context on the tool (although the work of Högberg and colleagues (2009) is exemplary in its integration of usewear and residue analysis). Also, despite the increased sensitivity of biochemical techniques, useful results from ancient material are seldom guaranteed. This is so because: a) the biochemistry of the micro-remains might have changed over time as a result of diagenesis, fossilization or soil chemistry, b) there is too little left for successful analysis, or c) the micro-residues are too 'messy' or contaminated (from use or from post-depositional/curational conditions) to provide conclusive biochemical results. 
Thus far, the best biochemical results for very old material $(60.5 \pm 1.9 \mathrm{ka})$ are obtained when macroscopic residues (relatively large quantities) are available for destructive analysis, and when there is a specific question at hand, for example, identifying the ingredients in adhesives (e.g., Cârciumaru et al., 2012; Charrié-Duhaut et al., in press). Yet, we know of few 'trouble-free' biochemical results relating to very old stone tools with animal residues such as bone, fat, animal tissue or collagen. With this initial paper we investigate the potential of detecting animal residues on stone tools in a non-destructive way, applying FTIR (Fourier transform infrared) spectroscopy to replicated stone points used for hunting and carcass processing, and we highlight potential archaeological applications, methodological improvements needed, and some difficulties associated with the technique.

FTIR spectroscopy has been used to analyse both inorganic and organic archaeological material (Cârciumara et al., 2012, Cotte et al., 2005; Mizzoni and Cesaro, 2007; Thompson et al., 2013, Yaroshevich, 2013). A benefit of this technique is that inorganic and organic phases can be analyzed simultaneously and a microscope attachment has the additional advantage of analyzing very small areas directly on an artefact without sample preparation or destruction. Infrared spectroscopy is also not hindered by fluorescence in the same way as Raman spectroscopy during the recording of spectra associated with organic materials (Prinsloo et al., 2013). Therefore, depending on biochemical preservation, FTIR spectroscopy is an ideal method to study micro-residues on prehistoric tools.

Preferably, an attenuated total reflection (ATR) microscope objective should be used to measure spectra directly in transmission or absorbance mode, but we have found that it is very difficult to record spectra on the uneven surfaces of the stone tools. It is even more difficult if the spot of interest is on the edge of a tool. Breakages can occur on the tool edge due to uneven pressure applied by the ATR objective on rough surfaces. However, using a microscope in reflectance mode results in a combination of reflection and transmission/absorbance FTIR spectra, which is not always as easy to interpret as directly measured transmission/absorbance spectra.

Recently it has been shown that FTIR specular reflectance spectra can be used to distinguish between minerals and for imaging material properties of bone specimens (Acerbo et al., 2012; Nicolson et al., 2012, Ostrooumov, 2009). In the identification of gemstones the technique is gaining ground, and has been in use for quite some time for remote sensing of minerals (e.g., Hainschwang and Notari, 2008; 
Clark 1999). In the field of heritage studies, where non-invasive techniques are imperative, FTIR reflectance spectroscopy was also found to be useful in the study of pigments and binders in spite of the difficulties in interpreting reflectance spectra (Buti et al., 2013; Lojewski et al., 2011; Miliani et al., 2012; Rosi et al., 2011; Unger et al., 2013).

Using experimental material, we attempt to establish whether reflection-based FTIR micro-spectroscopy can be used to study use-related animal residues adhering to stone tools. In contrast to genuine archaeological samples, the residues on the tools are known and reference material is readily available. Furthermore, post-depositional contamination is absent as the samples are only 10 years old and have been stored in sterile conditions. Therefore, we are able to assess the viability of FTIR reflectance spectra for distinguishing between bone, fat and protein residues.

\section{Materials and Methods}

\subsection{Stone tool points}

Six stone points, resembling those from the southern African Middle Stone Age and used during hunting and carcass processing experiments on parts of a blue wildebeest (Connochaetes taurinus) carcass (Lombard et al., 2004) were selected to test the ability of FTIR microscopy to identify animal residues that adhered to the points as a result of their use. A summary of the points selected for this study is provided in Table 1. Points 108 and 109 were used in thrusting experiments, 214, 217 and 219 in throwing experiments and Point 311 in a scraping experiment. In Figure 1 from left to right an example of a replicated spearhead used during the hunting experiments, a hafted spear stabbed into the shoulder of a blue wildebeest carcass and a short-handled replicated point used for scraping a portion of the carcass are shown.
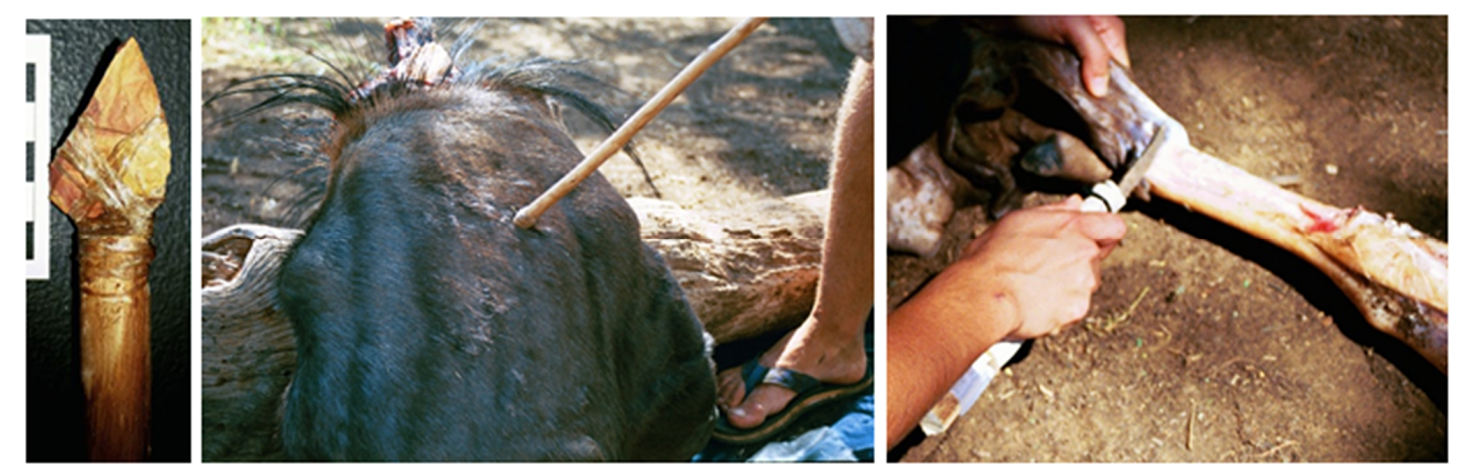

Figure 1: From left to right: an example of a replicated spearhead used during the hunting experiments, a hafted spear stabbed into the shoulder of a blou wildebeest carcass, a shorthandled replicated point used for scraping a portion of the carcass. 
Table 1: Summary of samples used in this study

\begin{tabular}{|c|c|c|c|c|c|}
\hline $\begin{array}{l}\text { Point } \\
\text { no. }\end{array}$ & Minerals used & Haft material & $\begin{array}{l}\text { Binding } \\
\text { material }\end{array}$ & Action & Contact materials \\
\hline 108 & $\begin{array}{l}\text { Medium-grained } \\
\text { quartzite }\end{array}$ & Commercial dowel & Sinew & Thrusting & Muscle, bone \\
\hline 109 & $\begin{array}{l}\text { Medium-grained } \\
\text { mudstone }\end{array}$ & $\begin{array}{l}\text { Combretum } \\
\text { erythrophylum }\end{array}$ & $\begin{array}{l}\text { Sinew, leather } \\
\text { thong }\end{array}$ & Thrusting & Muscle, bone \\
\hline 207 & $\begin{array}{l}\text { Fine-grained } \\
\text { quartzite }\end{array}$ & Commercial dowel & $\begin{array}{l}\text { Fibrous plant } \\
\text { twine }\end{array}$ & Throwing & Muscle, bone \\
\hline 214 & Fine-grained chert & $\begin{array}{l}\text { Tapiphyllum } \\
\text { parvifolium }\end{array}$ & Bark & Throwing & Muscle, bone \\
\hline 219 & $\begin{array}{l}\text { Fine-grained } \\
\text { hornfels }\end{array}$ & Commercial dowel & Leather thong & Throwing & Muscle, fat, bone \\
\hline 311 & $\begin{array}{l}\text { Fine-grained } \\
\text { hornfels }\end{array}$ & Canthium inerme & Leather thong & Scraping & Bone \\
\hline
\end{tabular}

\subsection{Contact materials}

During the hunting and butchery experiments, samples were collected from animal parts that came into contact with the stone points. These residues were stored on microscope slides for future use. We recorded transmission and reflectance infrared spectra of these materials as control samples for comparative purposes, and to observe and record potential differences between transmission and reflectance spectra.

\subsection{Experimental detail}

Infrared reflectance spectra were recorded using a Hyperion microscope attached to a Vertex 70v (Bruker Optics) spectrometer. The samples were placed directly under the 10x microscope objective and a spot selected for analysis. The spectra were then recorded using a $15 \mathrm{x}$ IR objective after optimising the focus to obtain the maximum signal. For small samples the aperture was decreased and background spectra were recorded under the same conditions. The recording time varied according to the quality of spectra obtained and ranged between 500-1000 scans and spectral resolution was $4 \mathrm{~cm}^{-1}$.

Infrared transmission/absorbance spectra of the powdered minerals from which the points were made were recorded using a diamond Golden Gate ATR cell (Bruker), which fits in the macro sample compartment of a Vertex 70v (Bruker Optics) spectrometer. The sample compartment was evacuated during acquisitions and the contact area between the sample and the diamond ATR crystal is $2 \mathrm{~mm}$ in 
diameter. Spectra were recorded with 32 acquisitions at $4 \mathrm{~cm}^{-1}$ resolution over a spectral range of $4000-600 \mathrm{~cm}^{-1}$.

\section{Results:}

\subsection{Minerals}

The stone points were produced from quartzite, mudstone, chert and hornfels. In many instances residues on the tools are very small and thinly spread on their surfaces, so that interference of the underlying rock can be expected in the spectra. Therefore it is necessary to record spectra of the different rock types before attempting to work with the residues so that potential interferences from peaks originating from the minerals are recognizable (also see Cesaro and Lemorini, 2012). In Figure 2 reflectance spectra of the minerals included in our study are presented and the peak positions in spectra of each mineral are summarized in Table 2. The strongest bands in all the spectra are located between $820-1290 \mathrm{~cm}^{-1}$ and originate from reststrahlen (residual rays) bands of the minerals. Although occurring at similar positions as true absorption/transmission bands, the origin of the bands are slightly different. Light is selectively reflected from the surface of a solid when the frequency of the light is nearly equal to the vibration frequency of the electrically charged atoms or ions, constituting the crystalline solid. The resulting reflection is known as reststrahlen.

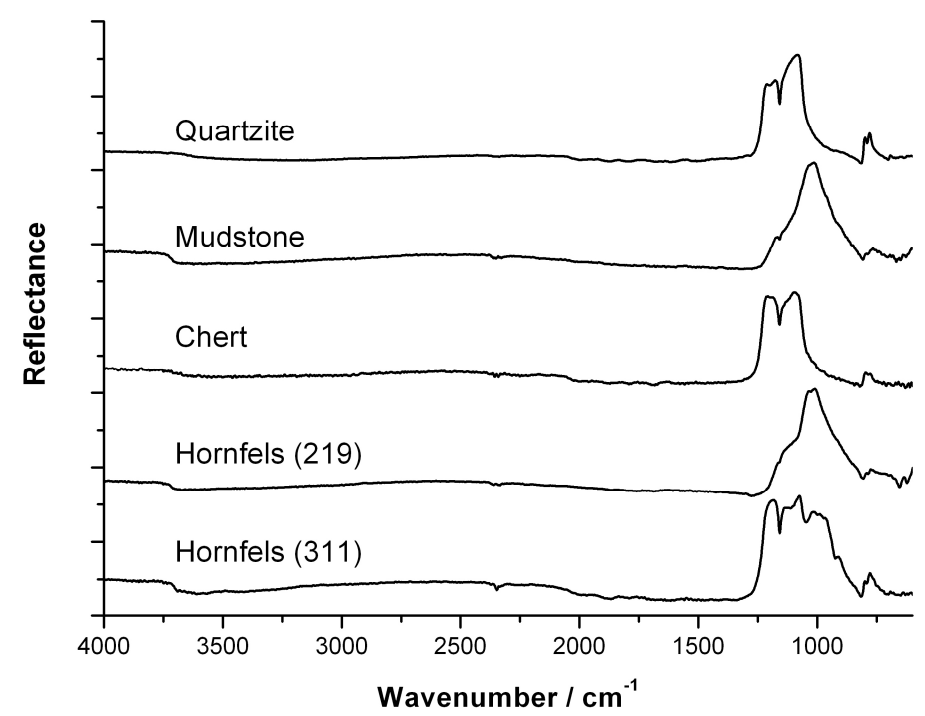

Figure 2: FTIR reflectance spectra of the raw materials used to produce the stone point replicates. 
Table 2: Comparision of reststrahlen and absorbance bands of the minerals involved

\begin{tabular}{l|ll}
\hline Mineral & Reststrahlen $\left(\mathbf{c m}^{-1}\right)$ & Absorbance/Transmission $\left(\mathbf{c m}^{-1}\right)$ \\
\hline Quartzite & $1176(\mathrm{vs}), 1084(\mathrm{vs}),, 797,778$ & $1162(\mathrm{sh}), 1067(\mathrm{vs}), 795,778($ doublet $)$, \\
& (doublet) & $694(\mathrm{sm})$ \\
Mudstone & $1171(\mathrm{sh}, \mathrm{sm}) 1018(\mathrm{vs})$ & $1096(\mathrm{sh}), 975(\mathrm{vs}), 770(\mathrm{br}, \mathrm{m}), 640(\mathrm{sm})$ \\
Chert & $1211,1175(\mathrm{split}, \mathrm{vs}), 1085$ & $1162(\mathrm{sh}), 1082(\mathrm{vs}), 795,778($ doublet $)$, \\
& $(\mathrm{vs}), 799,780($ doublet$)$ & $694(\mathrm{sm})$ \\
Hornfels (1) & $1019(\mathrm{vs})$ & $1102(\mathrm{sh}), 997(\mathrm{vs}), 777 \mathrm{sm})$ \\
Hornfels (2) & $1014,1076,1136,1186$ & $1164(\mathrm{sh}), 1091(\mathrm{sh}), 955(\mathrm{vs}), 764(\mathrm{~m}), 694$ \\
& & $(\mathrm{sm})$ \\
\hline
\end{tabular}

The difference between the processes of absorption and reflection is illustrated in Figure 3 where the single-channel spectra in the ATR cell (in vacuum) of the background and quartzite are compared to each other (left). It is clear that the two energy diagrams are exactly the same, except for the absorption around $1050 \mathrm{~cm}^{-1}$, which upon subtraction of the single-channel reference spectrum will give rise to the band representing $\mathrm{Si}-\mathrm{O}$ stretch vibrations in the resulting absorbance/transmission spectrum. In contrast, the single-channel spectra in specular reflectance mode (using the microscope) are compared to each other in Figure 3 (right) and it is clear that an increase in reflection is observed around $1050^{-1}$. To compare the two single channel spectra the spectrum of the sample was multiplied by 200 , indicating the low overall reflectance of the sample. However, the reststrahlen band is prominent and obviously has a different origin than absorption. (Note that in the single channel spectra recorded with the microscope, the overtone bands of diamond are absent, but peaks originating from $\mathrm{CO}_{2}$ and water vapour in the air are present.)
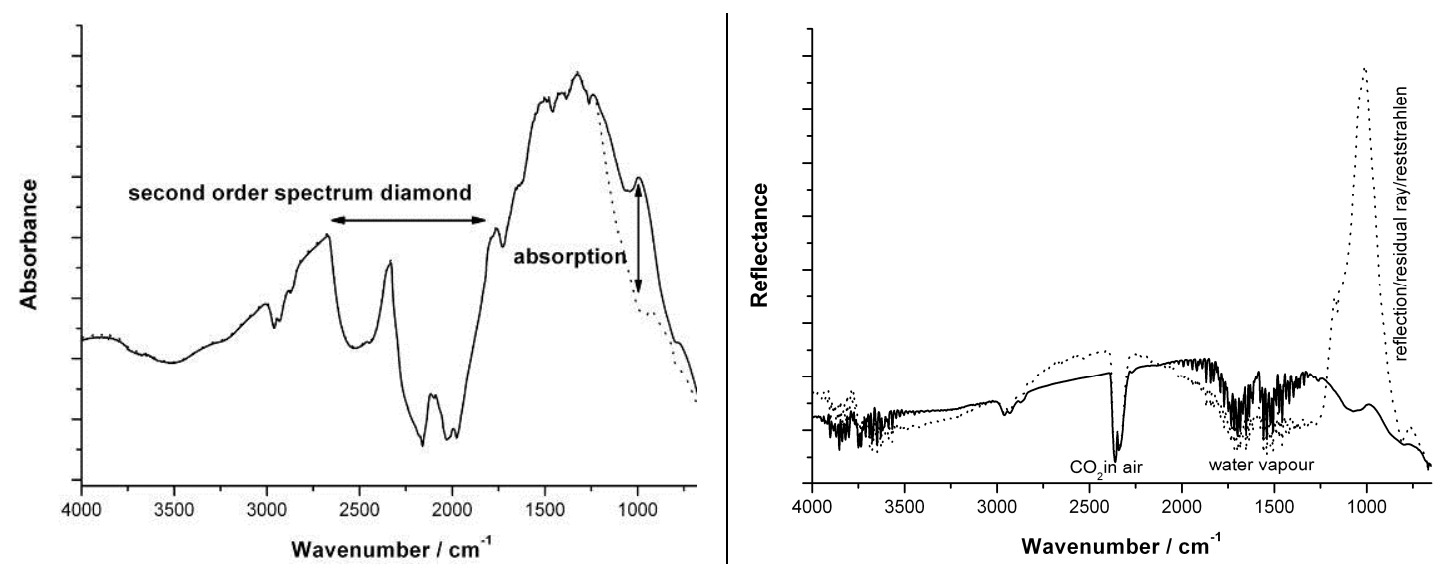

Figure 3: The single channel background and mudstone spectra recorded inside the instrument under vacuum in absorbance mode (left). The single channel background and mudstone (X200) spectra recorded in reflectance mode using the Hyperion microscope (right). 
Infrared absorbance/transmission spectra have been in use for a long time to identify minerals as aptly illustrated in Farmer (1974). In contrast, reflection spectra are not commonly used and literature on their application is scarce. Recently, however, reflection spectra have been shown to be a useful method for identifying minerals (Clark, 1999; Ostrooumov, 2009). Since no sample preparation involving destructive processes is necessary it is a good method for identifying gemstones (Hainschwang and Notari, 2008). In Figure 4 the absorbance FTIR spectra (measured with an ATR cell) of quartzite (left) and mudstone (right) are compared to their reflectance spectra recorded with the microscope in reflectance mode. It is clear that the main bands occur at more or less the same positions, but there are slight differences. The absorbance/transmission band is only dependent on absorption due to vibrations, but reststrahlen bands are a function of both absorption and dispersion, which is dependent on the refractive index of the material. In Table 2 the reflectance and absorbance spectra of the minerals used in this study are compared. It should be noted that small differences in reflection spectra recorded on different positions on natural samples will occur as rocks very rarely have homogeneous surfaces. It is interesting to note that the two samples classified as hornfels gave different reflectance spectra implying a possible misidentification. This illustrates the potential usefulness of FTIR reflectance spectroscopy in identifying minerals from archaeological contexts that are sometimes difficult to distinguish optically.
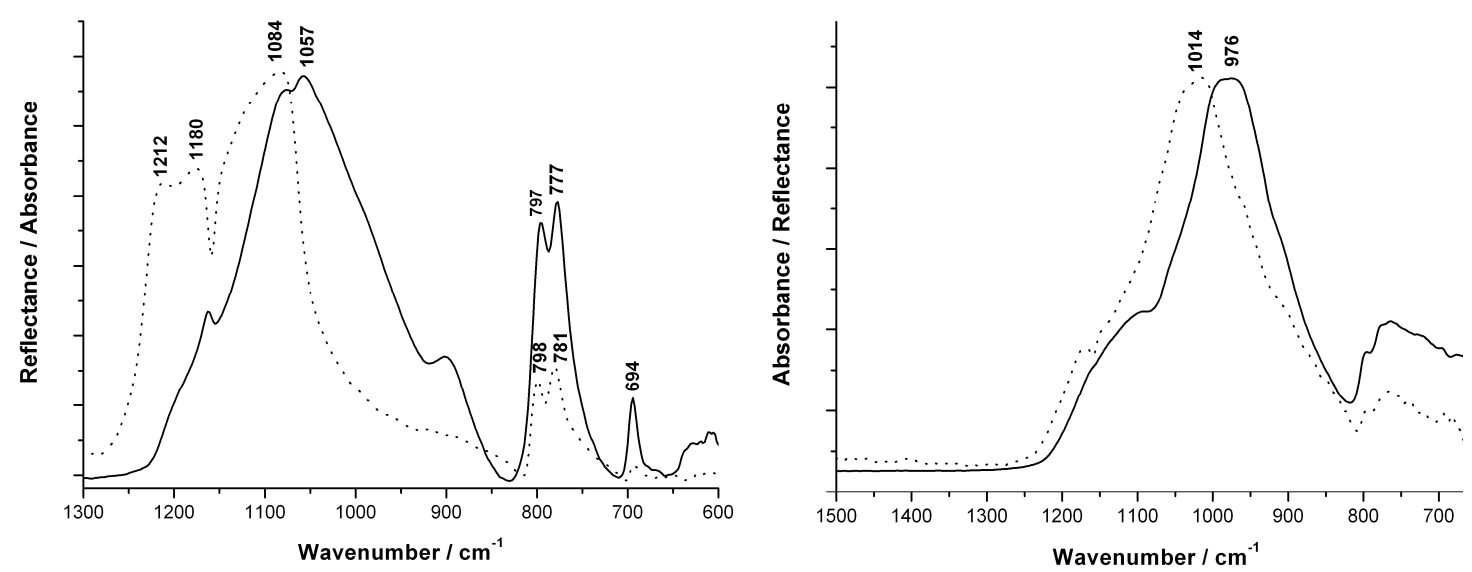

Figure 4: Comparison of the FTIR reflectance (dashed line) and absorbance (solid line) spectra of quartzite (top) and mudstone (bottom). 


\subsection{Control samples}

\subsubsection{Transmission/absorbance spectra}

The replicated stone points were used to strike, thrust and scrape portions of a wildebeest carcass, coming into contact with bone, fatty tissue and proteins originating from the animal's muscle, fat and skeleton (Fig. 5a) (for micromorphological description of these residues see Appendix A in Lombard 2008). In Figure $5 \mathrm{~b}$ transmission spectra recorded with the diamond ATR cell of these residues are presented. It is clear that there are distinct differences between the infrared spectra of bone, protein and fat. The spectrum of fat has characteristic bands at $1740 \mathrm{~cm}^{-1}$ (carbonyl stretch), $1466 \mathrm{~cm}^{-1},\left(\mathrm{CH}_{2}\right.$ and $\mathrm{CH}_{3}$ bending), $1175 \mathrm{~cm}^{-1}$ (C-O stretching) and $722 \mathrm{~cm}^{-1}\left(\mathrm{CH}_{2}\right.$ rocking), which in combination indicates the presence of a fat (Vandenabeele et al., 2000; Baeton, 1998). A feature of the spectrum is the very strong $\mathrm{C}-\mathrm{H}$ vibrations, typical of the long chain fatty acids. Although it is possible to use small shifts in the position of peaks to differentiate between different kinds of fats in perfect laboratory conditions using pure ingredients, it would be difficult for archaeological samples where the quality of spectra in general is poor (Prinsloo et al., 2013).

Prominent bands in protein spectra are the amide $\mathrm{I}(\mathrm{C}=\mathrm{O}$ stretching mode) at $1634 \mathrm{~cm}^{-1}$ and amide II (bending vibrations from C-N mode) at $1528 \mathrm{~cm}^{-1}$ typical of proteins (Gallagher website). The presence of these two bands in a spectrum indicates the presence of a protein, but identifying the exact protein would be difficult without quality spectra. Although present, $\mathrm{C}-\mathrm{H}$ vibrations are not as strong as in the spectrum of fat.

Seventy percent of bone is made up of the inorganic mineral hydroxyapatite, which includes calcium phosphate, calcium carbonate, calcium fluoride, calcium hydroxide and citrate. The other $30 \%$ of bone is composed of organic compounds, mostly proteins of which collagen is the most prominent. The mineralogical phase of bone is represented by the strong peak in the bone spectrum at $1004 \mathrm{~cm}^{-1}$ that originates from $\mathrm{PO}_{4}{ }^{-}$groups and the two peaks at 1410 and $872 \mathrm{~cm}^{-1}$ from calcium carbonate. The other peaks represent the organic phase with protein bands originating from collagen at 1642 and $1502 \mathrm{~cm}^{-1}$ (Acerbo et al., 2012; Nicolson et al., 2012, Thompson et al., 2013). 
a.

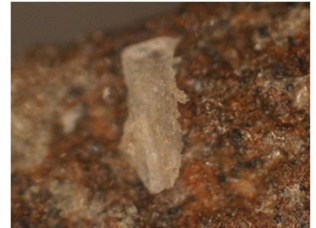

Bone

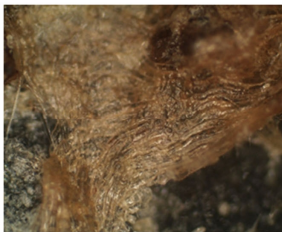

Muscle

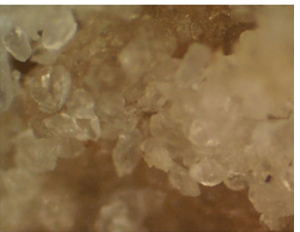

Fatty residue

b.

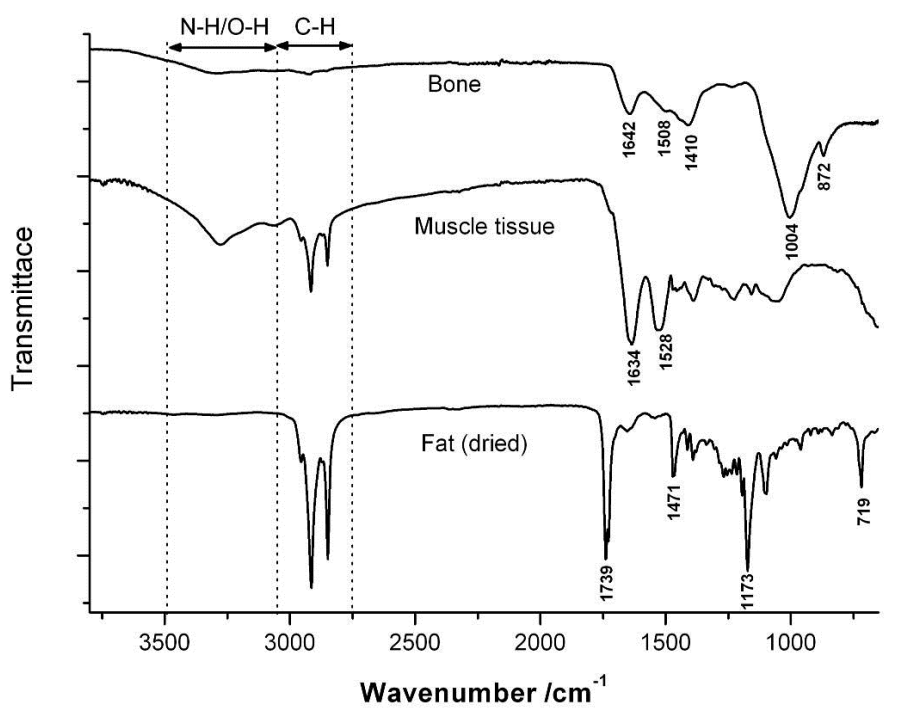

Figure 5: a) High magnification images of bone, muscle and fatty residues. b) Transmission FTIR spectra of wildebeest bone, muscle tissue and dried fat recorded using ATR diamond cell.

\subsubsection{Reflectance spectra}

Reflectance spectra of the same samples used for the transmission spectra were recorded using the $15 \mathrm{x}$ objective of the Hyperion microscope and the results are compared to the transmission data in Figure $6(\mathrm{a}-\mathrm{c})$. In Figure $6 \mathrm{a}$ the transmission and reflectance spectra of bone is compared and it is clear that the spectra are quite different. Although the peaks appear more or less at the same positions the bands have a derivative shape. Reflection of the surfaces of samples (specular reflection) is dependent on both the absorption index $(k)$ and the refractive index $(n)$ of a material. In the case of the absorption index being large $(k>>1)$, as for minerals and most inorganic salts, inverted or reststrahlen bands appear in the spectrum, for example the spectra in Figure 2. Another kind of distortion, namely derivative-like features of the spectra, occur for samples where $k<1$ such as most organic molecules (Fresnel's law). This distortion in specular reflectance spectra can in most cases be corrected by the 


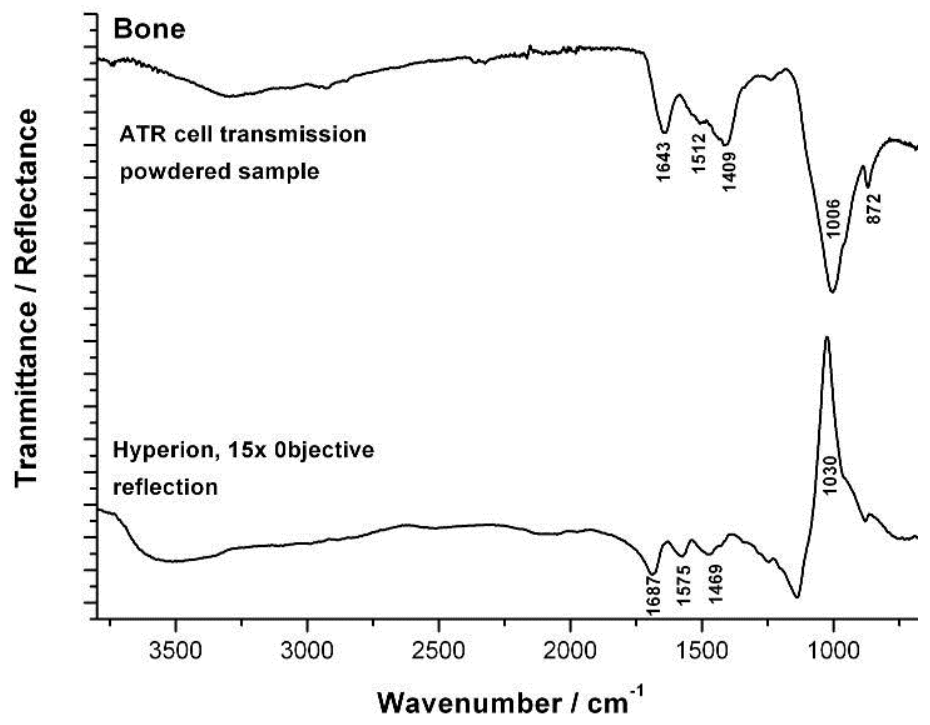

a.

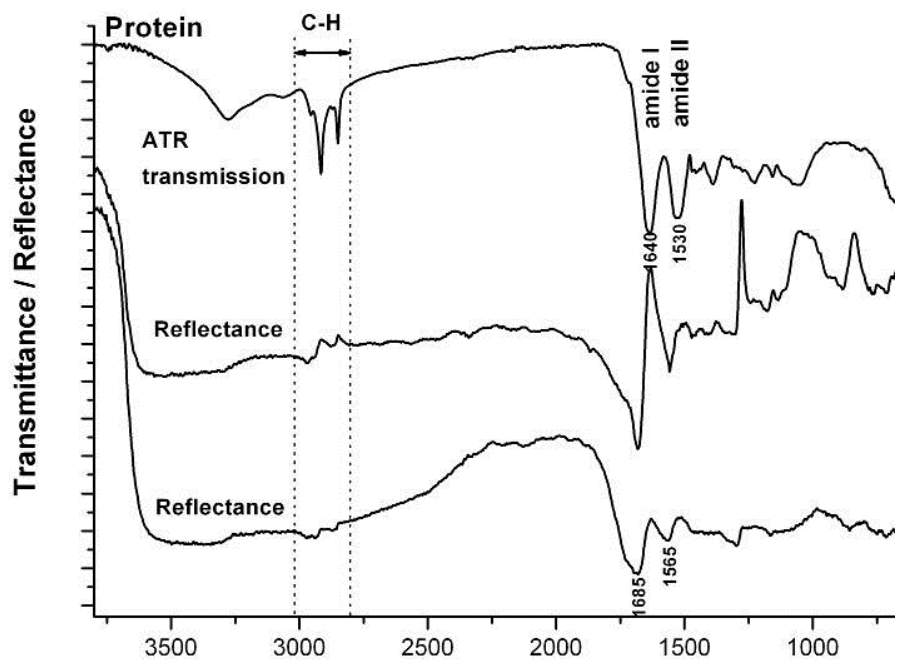

b.

Wavenumber $/ \mathrm{cm}^{-1}$

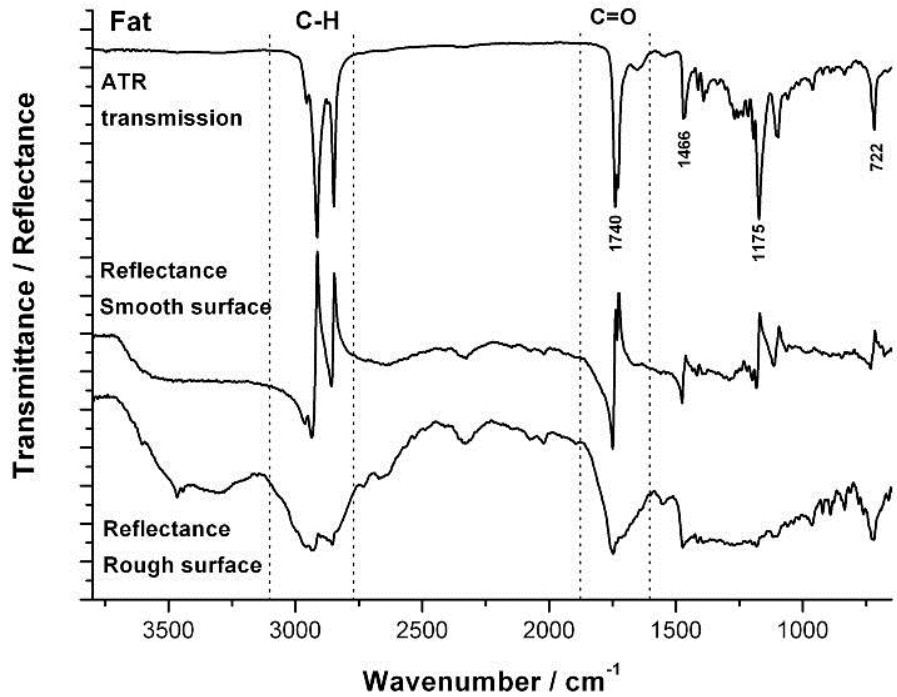

Figure 6. a) Comparison of transmission and reflectance spectra of bone, b) protein and c) fat 
application of the Kramers-Kronig transform, which is used to transform specular reflectance spectra into true absorption spectra. However, in many instances the distortion is not removed and for each specimen the transform has to be verified (Hainschwang and Notari, 2008). The same applies for the Kubelka-Munk conversion (Opus Software from Bruker), which converts diffuse reflectance spectra to true absorbance spectra. Many of the spectra obtained are also mixtures of reflectance and transmission spectra, complicating the matter further. Therefore it is more practical to use the spectra 'as is' for identification purposes, a practice also adopted in gemmology and in studies of pigments and binders (Buti et al., 2013; Hainschwang and Notari, 2008, Lojewski et al., 2011; Miliani et al., Rosi et al., 2011; 2012; Unger et al., 2013).

In Figure $5 \mathrm{~b}$ the transmission spectrum of blue wildebeest muscle tissue is compared to spectra recorded in reflectance mode. The spectrum in the middle was recorded on a very smooth piece of muscle tissue, while the bottom spectrum was recorded on an area that appeared rough. The middle spectrum displays the typical attributes of a derivative spectrum as smooth surfaces give rise to specular reflectance, while rough surfaces result in diffuse reflectance and transmission spectra. The appearance of a spectrum is thus highly dependent on the roughness of the sample surface and a variation of spectra is possible for the material of interest. It should be noted that when recording spectra in reflectance mode, absorptions due to organic material appears as transmission spectra with the peak maxima in the opposite direction as the reflectance peaks. Recently, papers have been published that did not take this into account (e.g., Cesaro and Lemorini, 2012).

The spectrum shown in the bottom of Figure $6 \mathrm{~b}$ has the general shape of the transmission spectrum recorded in the ATR cell except that the amide I and II peaks have shifted to higher wavenumbers (from 1640 and 1530 to 1685 and $1565 \mathrm{~cm}^{-1}$ ) and the peak between 3000-3800 attributed to $\mathrm{OH}$ absorptions is much more prominent. In general, reflection spectra probe the surfaces of molecules and the more intense water band is due to water absorbed on the surface. Figure $6 \mathrm{c}$ compares transmission and reflectance spectra of fat and again two kinds of spectra are possible: one with a derivative shape (smooth surface) and one that resembles a transmission spectrum (rough surface).

To summarise: for this study fat is recognised using FTIR spectroscopy by the presence of a peak between $1700-1780 \mathrm{~cm}^{-1}$, protein by the amide 1 and amide II 
peaks. In both cases the peaks may have a derivative-like shape. Bone is best recognised by comparing the reflectance bone spectrum graphically with the spectrum. The spectrum of the rock underneath might interfere with the recognition of bone and the protein bands of muscle tissue might also overlap with that of collagen. It should be noted that this allocation of characteristic bands is only relevant for this specific study where there is only three known ingredients. In archaeological samples a peak between 1700-1780 $\mathrm{cm}^{-1}$ may also indicate the presence of beeswax/resin/other ingredients with a $\mathrm{C}=\mathrm{O}$ as part of its structure, thus the morphological characteristics of the residues under higher magnification might hold valuable clues to their origin (e.g., Fig. 5a) (also see Appendix A in Lombard 2008 for morphological descriptions). Further experimentation is necessary to determine if other peaks in the spectra may assist to make more specific identifications.

\subsection{Analyses of the point replicates}

Since the residues are relatively 'fresh' (only ten years old) it was easy to recognize fat, muscle and bone microscopically (Fig. 5a). In Figure 7a-d representative spectra recorded on the stone points with accompanying low-power images of the measured 'spots' are shown. In Figure 7a the image taken with the video camera attached to the instrument on Point 108 was visually identified as a fat deposit by Marlize Lombard. The FTIR spectrum recorded on this spot appears to be a mixture of fat (peak at $1724 \mathrm{~cm}^{-1}$ ) and protein (muscle/meat) identified by the two amide peaks, as would be expected for a stone tool used for thrusting during hunting. The spectrum has derivative-like features, but mostly has the shape of a transmission spectrum which is in accordance with the rough appearance of the sample surface.

Point 109 was used for thrusting during the hunting experiments. The image in Figure $7 \mathrm{~b}$ was microscopically identified as muscle tissue on Point 109 and the FTIR spectrum of this residue displays the typical amide I and II peaks of a protein. A reflectance peak is also observed that probably originates from the rock underneath the residue. The spectra of the rock (mudstone) and bone are included for reference purposes. In the case of mudstone the strongest reflection peak is very near to that of bone and the two peaks may even overlap.

Point 311 was used for scraping bone during butchery experiments, and the residue in the image of Figure $7 \mathrm{c}$ was identified as fatty bone. The top spectrum in Figure $7 \mathrm{c}$ exactly matches that of bone as to be expected on a tool used for scraping. 
a) Point 108: Fat deposit
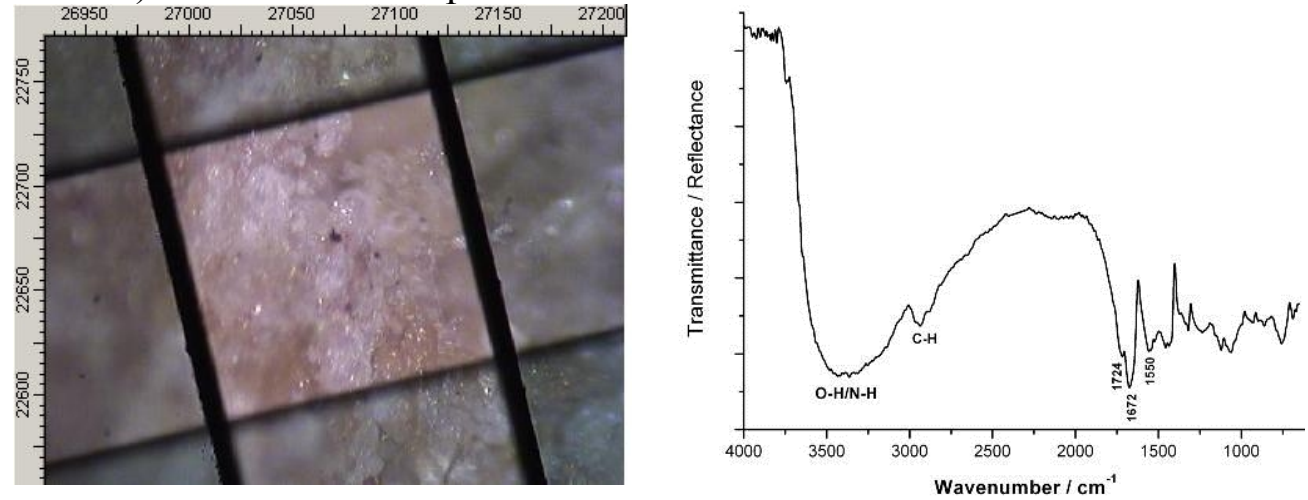

b) Point 109: Muscle tissue
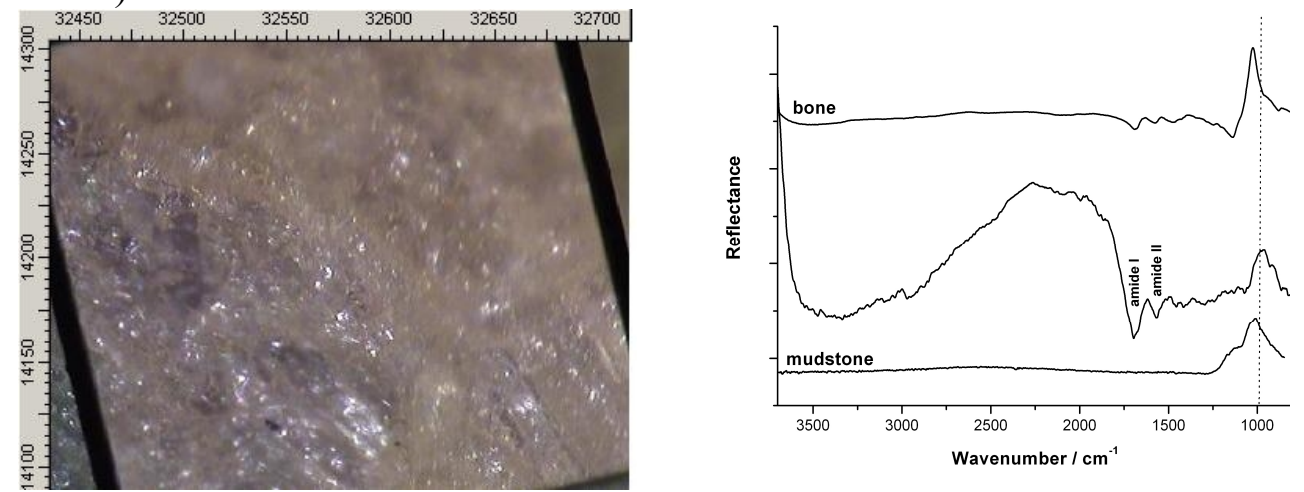

c) Point 311: Fatty bone
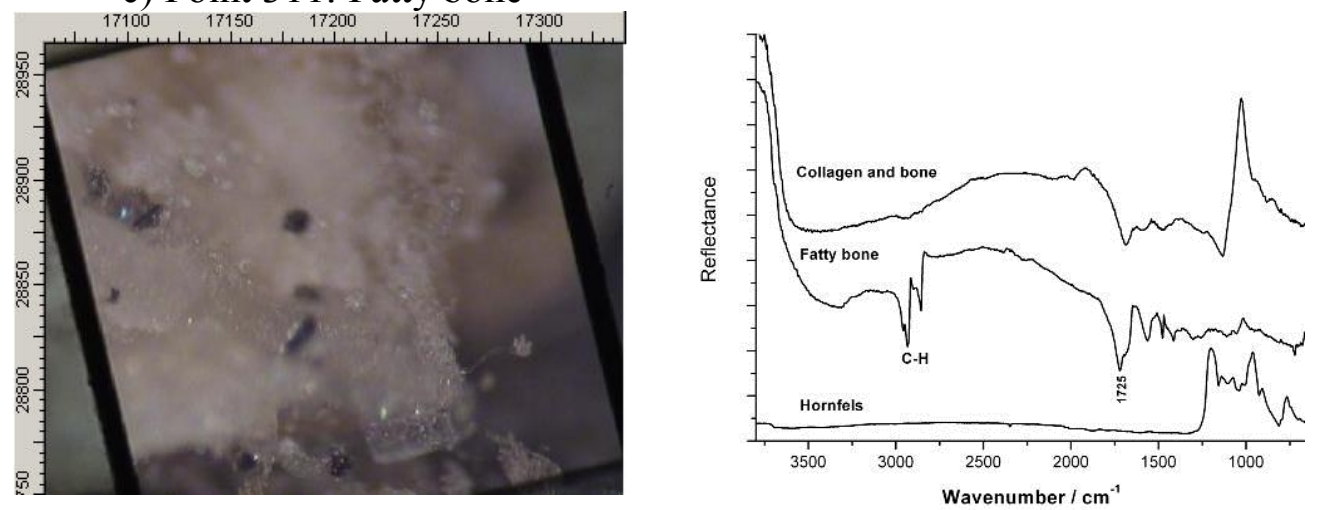

d) Point 214: Fat and bone
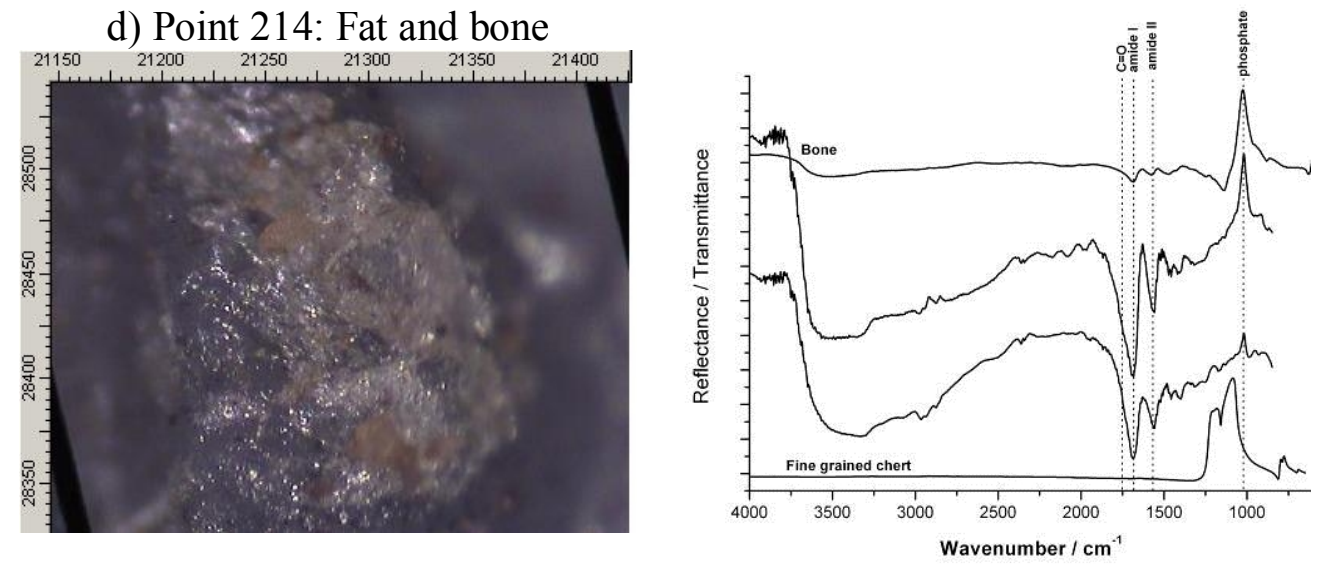

Figure 7: Examples of spectra recorded on the stone tool replicates. 
The bottom spectrum is a mixture of fat and protein with the fat component quite high as seen by the very strong $\mathrm{C}-\mathrm{H}$ vibrations typical of a fat. Residues on point 214, used for throwing at the carcass, were identified as fat and bone (image associated with Fig. 7d. The spectra of chert and bone are included for reference purposes, and it is clear that there are peaks that overlap as is the case for mudstone. The broadened amide 1 peak in the middle spectrum indicates that protein is also present

\section{Discussion}

We have demonstrated that FTIR reflectance spectroscopy can be used to identify animal micro-residues on stone tools and can thus verify and/or support their morphological identification based on light microscopy. However, a comprehensive collection of reference spectra has to be established before residue identification is possible and it is also necessary to establish a database of spectra for the substrate minerals to distinguish it from the spectra recorded for residues. The database of the minerals can also be utilized to identify rocks used for knapping in contexts where rock-types might be difficult to distinguish visually. Future work will expand the databases to include other residues and minerals.

FTIR spectroscopy also has its challenges. For example: the biochemical preservation of the residues must be intact for the technique to be successful, but can seldom be assumed for very old material. Analysts need to understand that, a) residues that adhere to stone tools as a result of ancient use are seldom 'pure', thus spectra might reflect a combination of residues (such as fat and bone or fat and protein), and b) the nature of the residue surface (e.g., smooth $v s$ rough or thin $v s$ thick) will affect the quality and character of the spectra. Post-depositional and curational contamination must at all times be considered, thus spectra of single residues on single tools, without the consideration of concomitant residues, usewear and their distribution patterns on the tools, might have diminished interpretative value.

Nonetheless, we were able to establish a link between the micro-morphology of some animal residues adhered to stone tools as a result of use and their chemical compositions. This is important as the experiments conducted in this study are for relatively fresh samples that have not been exposed to contamination or degradation processes, while very old archaeological samples would have been exposed to many 
different environmental conditions before and after burial. Moving to archaeological samples, the biochemical information that can be gained from FTIR spectroscopy will be invaluable in evaluating degradation processes that have taken place and reconciling the morphological identification of a residue with its chemical signature. In order to understand possible chemical changes the next step will be to broaden the study to residues exposed to accelerated degradation conditions that mimic what happens during burial such as exposure to bacteria, fungi, site specific ground water etc.

\section{Conclusions}

We conclude that micro-morphological and FTIR results are complementary, rather than duplication or replacement studies. For example, both methods can demonstrate the presence of fat, but each provides additional information, not provided by the other. FTIR reveals aspects of the biochemistry of the residue, which can be ambiguous with similar spectra also indicating other possible substances, but in combination with the morphological characteristics of animal fat as recorded on experimental stone tools, a more secure interpretation can be made, especially if the residue is closely associated with other animal residues such as bone or muscle tissue/protein. A multi-stranded approach to microscopy also reveals striations and fractures associated with the micro-residues (e.g., Lombard, 2011). FTIR may indicate what was scraped by a scraper, but microscopy can demonstrate the direction of the movement across the bone. FTIR also provide information on the mineralogy of the underlying rocks, which use-trace microscopy cannot.

Thus, we propose that, ultimately, the combination of methods can provide a rich history of stone artefacts without having to destroy or disturb aspects of the history. We are hopeful that with further experimentation and thoroughly designed research questions FTIR spectroscopy can make a considerable contribution towards understanding biochemical degradation processes of residues. 


\section{Acknowledgements}

The authors wish to thank the NRF, and the Universities of Pretoria, the Witwatersrand and Johannesburg for their financial support. Results and inferences are, however, those of the authors and not the funding or supporting institutions. 


\section{References}

Acerbo, A.S., Lawrence Carr G., Judex S. and Miller L.M., 2012. Imaging the material properties of bone specimens using reflection-based infrared microscopy. Anal. Chem. 84 (8) 3607-3613 DOI: 10.1021/ac203375.

Buti, D., Rosi, F., Brunetti, B.G., and Miliani C., 2013. In-situ identification of copper-based green pigments on paintings and manuscripts by reflection FTIR. Anal Bioanal Chem. 405:2699-2711. DOI 10.1007/s00216-013-6707-6

Cârciumara, M., Ion, R., Niţu, E., Ştefănescu R., 2012. New evidence of adhesive as hafting material on Middle and Upper Palaeolithic artefacts from Gura Cheii-Râşnov Cave (Romania). J. Archaeol. Sci., 39, 1942-1950.

DOI: $10.1016 /$ j.jas.2012.02.016

Cesaro N.C. and Lemorini C., 2012. The function of prehistoric lithic tools: A combined study of use-wear analysis and FTIR microspectroscopy, Spectrochim. Acta A Mol. Biomol. Spectrosc., 86, 299-304. DOI:10.1016/j.saa.2011.10.040

Charrié-DuhautA, Porraz, G., Cartwright, CR., Igreja, M., Connan, J., Poggenpoel, C., Texier, P-J., 2013. First molecular identification of a hafting adhesive in the Late Howiesons Poort at Diepkloof Rock Shelter (Western Cape, South Africa). J. Archaeol. Sci. in press

Clark, R.N., 1999. Chapter 1: Spectroscopy of Rocks and Minerals, and Principles of Spectroscopy, in Manual of Remote Sensing, Volume 3, Remote Sensing for the Earth Sciences, (A.N. Rencz, ed.) John Wiley and Sons, New York, p 3- 58, 1999. http://speclab.cr.usgs.gov

Cotte M.; Dumas P.; Richard G.; Breniaux R., Walter P., 2005. New insight on ancient cosmetic preparation by synchrotron-based infrared microscopy. Anal. Chim. Acta, 553 (1-2) 105-110 DOI: 10.1016/j.aca.2005.07.067

Farmer V.C. (ed.) The Infrared Spectra of Minerals, Mineralogical Society, London, England, 1974. 
Gallagher W., FTIR analysis of protein structure.

http://www.chem.uwec.edu/Chem455_S05/Pages/Manuals/FTIR_of_proteins.pdf

Hainschwang T., Notari F., 2008. Specular reflectance infrared spectroscopy - a review and update of a little exploited method for gem identification. The Journal of Gemmology, 31 (1-2), 23-29.

Hardy, B.L., Garufi, G.T. 1998. Identification of woodworking on stone tools through residue and use-wear analyses: experimental results. J. Archaeol. Sci. 25, 177-184.

Hardy, B.L., Moncel, H-M., 2011. Neanderthal use of fish, mammals, birds, starchy plants and wood 125-250,000 years ago. PLoS ONE 6(8): e23768.

doi:10.1371/journal.pone.0023768 DOI: 10.1006/jasc.1997.0234

Högberg, A., Puseman, K., Yost, C., 2009. Integration of use-wear with protein residue analysis: a study of tool use and function in the south Scandinavian Early Neolithic. J. Archaeol. Sci.. 36, 1725-1737. DOI: 10.1016/j.jas.2009.03.030

Korte, E.H., Röseler, A., 2005. Infrared reststrahlen revisited: commonly disregarded optical details related to $\mathrm{n}<1$. Anal. Bioanal. Chem. 382 (8) 1987-1992. DOI: $10.1007 / \mathrm{s} 00216-005-3407-\mathrm{x}$

Langejans, G.H.J., 2011. Discerning use-related micro-residues on tools: testing the multi-stranded approach for archaeological studies. J. Archaeol. Sci. 38, 985-1000. DOI: $10.1016 /$ j.jas.2010.11.013

Langejans, G.H.J., 2012. Middle Stone Age pièces esquillées from Sibudu Cave, South Africa: an initial micro-residue study. J. Archaeol. Sci. 39, 1694-1704. DOI: 10.1016/j.jas.2011.12.036

Li M., Yang, X., Ge, Q., Ren, X., Wan, Z., 2013. Starch grains analysis of stone knives from Changning site, Qinghai Province, Northwest China. J. Archaeol. Sci. 40, 1667-1672. DOI: 10.1016/j.jas.2012.11.018 
Lojewski T., Bagniuk J., Kolodziej A., Lojewska A., 2011. Reflective and photoacoustic infrared spectroscopic techniques in assessment of binding media in paintings. Appl. Phys. A 105:753-761. DOI 10.1007/s00339-011-6512-z

Lombard, M. 2008. Finding resolution for the Howiesons Poort through the microscope: micro-residue analysis of segments from Sibudu Cave, South Africa. J. Archaeol. Sci. 35: 26-41.

Lombard, M. 2011. Quartz-tipped arrows older than $60 \mathrm{ka}$ : further use-trace evidence from Sibudu, KwaZulu-Natal, South Africa. J. Archaeol. Sci. 38, 1918-1930. DOI: 10.1016/j.jas.2011.04.001

Lombard M., Parsons I. van der Ryst M.M., 2004. Middle Stone Age lithic point experimentation for macro-fracture and residue analyses: the process and preliminary results with reference to Sibudu Cave points. S. Afr. J. Sci. 100: 159-166.

Lombard, M., Wadley, L., 2007. The morphological identification of micro-residues on stone tools using light microscopy: progress and difficulties based on blind tests. J. Archaeol. Sci. 34, 155-165. DOI: 10.1016/j.jas.2006.04.008

Miliani C., 'Rosi F., Daveri A., Brunetti B.G., 2012. Reflection infrared spectroscopy for the non-invasive in situ study of artists' pigments. Appl. Phys. A. 106:295-307. DOI 10.1007/s00339-011-6708-2

Mizzoni, F.; Cesaro, S.N., 2007. Study of the organic residue from a 2600-year old Etruscan plumpekanne. Spectrochim. Acta A Mol. Biomol. Spectrosc., 68 (2) 377381. DOI: $10.1016 /$ j.saa.2006.12.005

Monnier, G.F., Ladwig, J.L., Porter, S.T. 2012. Swept under the rug: the problem of unacknowledged ambiguity in lithic residue identification. J. Archaeol. Sci. 39, 3284-3300. DOI: 10.1016/j.jas.2012.05.010

Nicholson C.L., Firth E.C., Waterland M.R., Jones G., Ganesh S. Stewart R.B., 2012. Innovative approach to investigating the microstructure of calcified tissues using 
specular reflectance Fourier Transform-Infrared microspectroscopy and discriminant analysis. Anal. Chem. 84, 3369-3375. dx.doi.org/10.1021/ac300123r

Prinsloo L.C., Tournié A., Colomban Ph, Paris C., Bassett S.T., 2013. In search of the optimum Raman/IR signatures of potential ingredients used in San/Bushman rock art paint. J. Archeol. Sci. 40, 1981-1990. DOI: 10.1016/j.jas.2013.02.010

Ostrooumov M., 2009 Infrared reflection spectrometry analysis as a non-destructive method of characterising minerals and stone materials in geoarchaeological and archaeometric applications. Geoarchaeology: An International Journal 24 (5), 619637. DOI: $10.1002 /$ gea.20277

Rosi F., Federici A., Brunette B.G., Sgamellotti A., Clememti S., Miliani C., 2011. Multivariate chemical mapping of pigments and binders in easel painting crosssections by micro IR reflection spectroscopy. Anal. Bioanal. Chem. 399: 3133-3145. DOI $10.1007 / \mathrm{s} 00216-010-4239-\mathrm{x}$

Thompson T.J.U., Islam M., Bonniere M., 2013. A new statistical approach for determining the crystallinity of heat-altered bone mineral from FTIR spectra. J. Archeo Sci., 40, 416-422. DOI: 10.1016/j.jas.2012.07.008

Unger M., Mattson E., Schmidt-Patterson C., Alavi Z., Carson D., Hirschmugl C.J., 2013. Synchrotron-based multiple-beam FTIR chemical imaging of a multi-layered polymer in transmission and reflection: towards cultural heritage applications. Appl. Phys. A 111:135-145. DOI 10.1007/s00339-012-7481-6

Wadley, L., Lombard, M., Williamson, B. 2004. The first residue analysis blind tests: results and lessons learnt. J. Archaeol. Sci. 31, 1491-1501.

DOI:10.1016/j.jas.2004.03.010

Wadley, L., Lombard, M. 2007. Small things in perspective: the contribution of our blind tests to micro-residue studies on archaeological stone tools. J. Archaeol. Sci. 34, 1001-1010. DOI: 10.1016/j.jas.2006.09.016 
Yaroshevich A., Nadel D., Tsatskin A., 2013. Composite projectiles and hafting technologies at Ohalo II (23 ka, Israel): analyses of impact fractures, morphometric characteristics and adhesive remains on microlithic tools. J. Archaeol. Sci. in press. http://dx.doi.org/10.1016/j.jas.2013.05.017 


\section{Figure captions}

Figure 1: From left to right: an example of a replicated spearhead used during the hunting experiments, a hafted spear stabbed into the shoulder of a blue wildebeest carcass, a short-handled replicated point used for scraping a portion of the carcass.

Figure 2: FTIR reflectance spectra of the raw materials used to fabricate the lithic point replicates.

Figure 3: The single channel background and mudstone spectra recorded inside the instrument under vacuum in absorbance mode (left). The single channel background and mudstone (X200) spectra recorded in reflectance mode using the Hyperion microscope (right).

Figure 4: Comparison of the FTIR reflectance (dashed line) and absorbance (solid line) spectra of quartzite (left) and mudstone (right).

Figure 5 a. High magnification images of bone, muscle and fatty residues. b) Transmission FTIR spectra of wildebeest bone, muscle tissue and dried fat recorded using ATR diamond cell. b Transmission FTIR spectra of wildebeest bone, muscle tissue and dried fat.

Figure 6: a) Comparison of transmission and reflectance spectra of bone, b) protein and c) fat

Figure 7: A selection of spectra recorded on the lithic point replicates together with the accompanying low magnification microscope images. 